\title{
Valorization of pomegranate peel balls as bioadsorbents of dyes in aqueous media
}

\author{
Radhia Msaadi ${ }^{1, *}$, Wafa Sassi ${ }^{1}$, Jean-Yves Hihn ${ }^{2}$, Salah Ammar ${ }^{1}$, Mohamed M. Chehimi ${ }^{3, *}$ \\ ${ }^{1}$ Faculté des Sciences, Unité de Recherche Électrochimie, Matériaux et Environnement \\ UREME (UR17ES45), Université de Gabès, 6000 Gabès, Tunisia \\ ${ }^{2}$ Institut UTINAM, CNRS UMR 6213, Université Bourgogne Franche Comte, 16 route de \\ Gray, 25030 Besançon Cedex, France \\ ${ }^{3}$ ICMPE (UMR 7182), CNRS, UPEC, Université Paris Est, F-94320 Thiais, France;
}

\begin{abstract}
There is an ever-growing demand for adsorbents in environmental protection processes such as removal of organic and inorganic hazardous compounds. One emerging aspect of this remedy is to explore the propensity of new, sustainable and low-cost materials derived from the biomass. Herein, pomegranate peel balls were evaluated as bioadsorbents for removal of Methylene Blue (MB) dye, a model pollutant, from aqueous solutions. Adsorption kinetics were investigated in relation to temperature, contact time and $\mathrm{pH}$ of the solution. The results were found to fit pseudo-second order kinetics. The maximum adsorption capacity of the peel balls for $\mathrm{MB}$ was found to be $15.8,15.6,14.9$ and $14.5 \mathrm{mg} / \mathrm{g}$ at $25,35,45$ and $55^{\circ} \mathrm{C}$, respectively. Thermodynamic studies indicated that the sorption reaction was spontaneous and exothermic. Mechanisms of sorption include physical adsorption.

This work conclusively shows that in countries where pomegranate is available, the waste generated by the fruit peel could be considered for future water filtration and environmental protection.
\end{abstract}

\section{Keywords}

Pomegranate peel; waste to wealth; biosorbent; Methylene Blue; kinetics

Correspondence:

Radhia Msaadi: radhiaradhia44@gmail.com, Mohamed M. Chehimi : chehimi@icmpe.cnrs.fr 
32

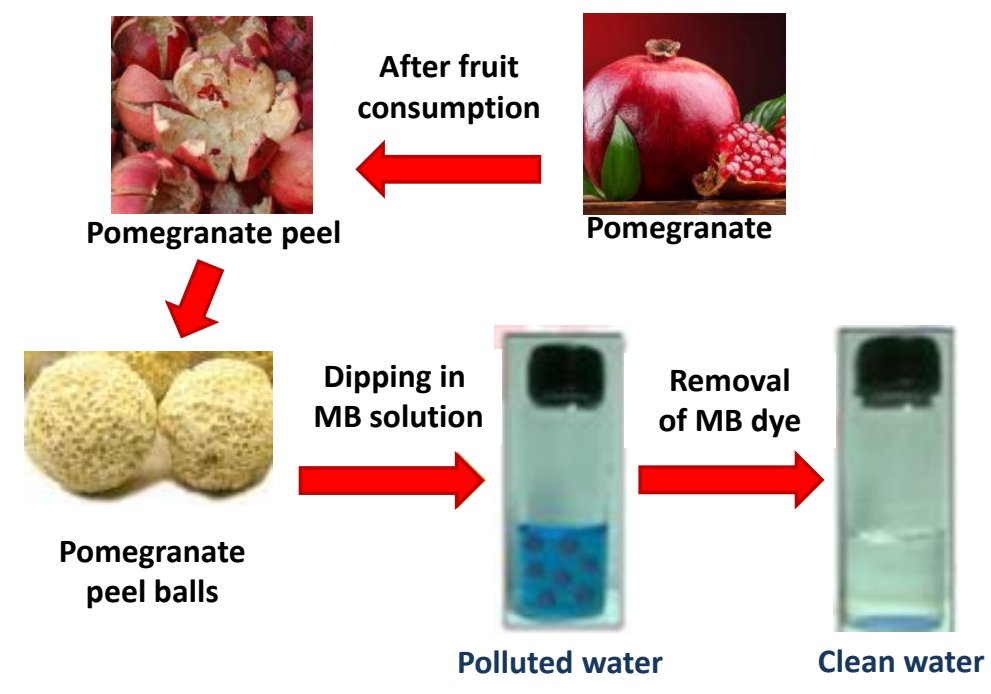

33

34

35 


\section{Introduction}

Water pollution from industrial discharges is a serious problem in several countries. It presents a real danger to mankind and the environment due to persistence and in some cases low bio-degradability $[1,2,3]$. Particularly, industrial wastewater polluted with dyes has been extensively studied. In order to reduce the harmful effects of these pollutants, several wastewater treatment processes, such as biological processes, give unsatisfactory results due to the composition of these discharges in toxic materials and dyes that are difficult to biodegrade $[4,5,6]$. Adsorption is one of the most widely used techniques and is easy to implement. The removal of dyes from aqueous solutions by adsorption on various solid materials, especially activated carbon, has been the subject of numerous studies $[7,8,9,10,11]$. Adsorption of organic pollutants such as dyes on activated carbon has proven to be a very efficient treatment technique. However, recalcitrant dyes require overdosing of carbon for higher efficiency, making the cost of the operation excessive. Moreover, regeneration of activated carbon is also a tricky operation and costly. Due to these shortcomings, the usefulness of carbon adsorbents is still under debate $[12,13]$. As an alternative, low-cost adsorbent materials raised much interest for wastewater treatment [14,15], particularly in view of efficiently removing dyes [16] and other hazardous compounds [17]. Commonly used adsorbents are tea leaves [18,19,20,21], coconut shells [22], coffee beans [23,24], and corn cobs [25,26] among numerous biomass-derived materials [27,28,29,30]. In addition, the recovery of food waste without generating pollutants is a major challenge and is recommended for sustainable industrial development in order to protect the environment.

Therefore, it is necessary to continue testing emergent low-cost, economical, abundant and readily available bioresourced adsorbents for wastewater treatment, e.g. removal of dyes. As energy and pollution are important issues, the resources available in a given region or country need to be explored. Mediterranean countries are well-known for the production of numerous fruits, the wastes of which after consumption could advantageously be employed to address environmental issues. Pomegranate is massively produced in the Mediterranean basin, and consumed as table fruit in several recipes, and pressed to obtain fresh, tasty juice. Production is estimated at 2.5 million metric tons/year. While widely available in Mediterranean countries and other regions such as the Middle East, India (33\%), Iran (37\%), and Turkey $(13 \%)$ to a lesser extent pomegranate is also produced in California, Mexico, Russia, and Japan [31]. Particularly, in Tunisia, pomegranate production is about 75000 tons/year in 2019 and mainly located in Gabès, South-East Tunisia. The region of Gabès contains 35\% of the 
national pomegranate producers in Tunisia. Only recently, pomegranate peels have been considered for valorization. Peels are a source of natural products such as citric acid [32] and polyphenols [33], provide tannins for adhesive formulation [34], and could be exploited in nanomaterial synthesis [35].They have also been considered as low-cost agrowaste in water treatment [36], particularly for the removal of dyes [37,38,39] including methylene blue [39]. However, reports in the literature considered only dried and then milled pomegranate peels (if carbonized derived materials are excluded). In this work, a completely different strategy is proposed for the preparation of adsorbents from pomegranate peels, based on lyophilization of frozen pomegranate peel paste. This option leads to sublimation of frozen water, thus resulting in porous adsorbents. This is what has motivated this sustainable developmentoriented research.

In this study, we used pomegranate peel as an agrowaste to prepare pomegranate peel ball bioadsorbent. The pomegranate peel balls were tested for the removal of methylene blue from aqueous solutions.

The influences of solution $\mathrm{pH}$, initial concentration of methylene blue, contact time and temperature on removal of the dye were thoroughly investigated. Kinetic models and constants, as well as adsorption thermodynamic properties, were assessed.

\section{Experimental}

\subsection{Instrumentation and characterization}

Methylene blue dye, a product of Alfa Aesar company, was used as received without any purification. A stock solution of $1000 \mathrm{mg} . \mathrm{L}^{-1}$ was prepared by dissolving the required amount of color in ultrapure water. The working solution of the desired concentrations was obtained by successive dilutions of the stock solution. The concentration of MB in solution before and after adsorption were determined at the maximum wavelength $\lambda=664 \mathrm{~nm}$, using a UV spectrophotometer (Shimadzu UV-3101PC)

An AK Alpha instrument (Thermo), fitted with a monochromated Al Ka X-ray source $(\mathrm{h} \nu=1486.6 \mathrm{eV}$, spot size $=400 \mu \mathrm{m})$, was used for XPS measurements. A flood gun was employed for static charge compensation. The analyzer was operated at 80 and $200 \mathrm{eV}$ pass energy for the narrow regions and survey spectra, respectively. Elemental atomic concentrations were computed using the integrated peak areas and the corresponding 
sensitivity factors provided by the manufacturer. Fourier Transform Infrared (FTIR) spectra were recorded on a Perkin-Elmer Spectrum 100 FTIR spectrophotometer in the range of 400$4000 \mathrm{~cm}^{-1}$ after deposition of the sample on a diamond substrate.

\subsection{Preparation of pomegranate peel balls.}

The pomegranate peel was collected and washed with ultra-pure water to remove soluble materials, dust and impurities, then dried at room temperature for 2 weeks. It was then dried for two days at room temperature, away from dust, and crushed with mortar. The peel was sieved through a mesh of porosities equal to or less than $80 \mu \mathrm{m}$. To prepare pomegranate peel balls, 20 grams of pomegranate peel powder were added to 100 milliliters of distilled water to make a paste. After that, the paste was made into small balls and left to freeze in order to turn water into ice. The frozen peel balls were then lyophilized in order to sublimate ice. This process permitted the final porous pomegranate peel balls to be obtained.

\subsection{Batch adsorption experiments}

To study the effect of important parameters such as $\mathrm{pH}$, contact time, initial concentrations of color and temperature on the adsorptive removal of methylene blue, batch experiments were conducted. The effect of $\mathrm{pH}$ on methylene blue removal was studied over a $\mathrm{pH}$ range of 1 10. The initial $\mathrm{pH}$ of the solution was adjusted by addition of aqueous solution of $\mathrm{HNO}_{3}$ or $\mathrm{NaOH}(1 \mathrm{M})$. The adsorption kinetics were determined by mixing $20 \mathrm{~mL} \mathrm{MB}$ at $40 \mathrm{mg} / \mathrm{L}$ concentration with a mass of $50 \mathrm{mg}$ biosorbent in pyrex beakers at room temperature. This mixture was stirred at a constant rate of $200 \mathrm{rpm}$. The samples were taken at different time intervals from 0 - 300 seconds, while the supernatant was analyzed by UV-Visible spectroscopy $\lambda=665 \mathrm{~nm}$ (corresponding to maximum absorbance).

The percentage of dye removal (\% of color removal) and the adsorbed amount (qe) were calculated using the equations (1) and (2)

$$
\% \text { Color removal }=\frac{C_{0}-C_{t}}{C_{0}} * 100
$$

$$
q e=\frac{\left(C_{0}-C_{e}\right) V}{m}
$$

where $C o$ and $C t\left(\mathrm{mg} \mathrm{L}^{-1}\right)$ are the initial $\mathrm{MB}$ concentration and concentration at time $t$, respectively, $\mathrm{V}(\mathrm{L})$ is the volume of solution, and $\mathrm{m}(\mathrm{g})$ is the weight of adsorbent. 


\subsection{Regeneration of bioadsorbents}

In order to test the reusability of the bio-balls, cycles of adsorption-desorption experiments were carried out [40]. First, the Methylene Blue adsorption experiments were carried out in batches under the optimal conditions described in the previous section using $20 \mathrm{~mL}$ of $40 \mathrm{mg} / \mathrm{L}$ of $\mathrm{MB}$, with a contact time of 60 minutes. Desorption was performed by placing the bio-balls in $20 \mathrm{~mL}$ of $0.1 \mathrm{M} \mathrm{HCl}$. Then, the bio-adsorbent was washed with bi-distilled water at neutral $\mathrm{pH}$, and this adsorption-desorption process was performed five times using the same adsorbent.

\section{Results and Discussion}

\subsection{IR analysis}

An FTIR spectrophotometer was used to determine the differences in functional groups before and after the sorption process on MB. Figure 1 shows the FTIR spectra of pomegranate peel balls after and before adsorption of $\mathrm{MB}$, which exhibit a broad and strong absorption peak at around $3320 \mathrm{~cm}^{-1}$ assigned to the stretching vibration peak of $-\mathrm{OH}$. The band observed at 2940 $\mathrm{cm}^{-1}$ related to $\mathrm{C}-\mathrm{H}$ stretching vibration. The existence of vibrational stretching of the $\mathrm{C}=\mathrm{O}$ group can be confirmed by IR absorption bands at 1736 and $1613 \mathrm{~cm}^{-1}$ (Figure 1a, upper spectrum). The absorption bands at 1442, 1321 and $1200 \mathrm{~cm}^{-1}$ are assigned to C-O-H bending vibration, $\mathrm{O}-\mathrm{H}$ bending vibration, and $\mathrm{C}-\mathrm{O}$ group stretching vibration, respectively. A band appearing at $1013 \mathrm{~cm}^{-1}$ is assigned to the stretching vibration $\mathrm{C}=\mathrm{O}$. The band at $1600 \mathrm{~cm}-1$ could be assigned to asymmetric and symmetric vibrations of the ionized carboxylic group $\mathrm{O}=\mathrm{C}_{-} \mathrm{O}^{-}$[39]. After adsorption of Methylene Blue, Figure $1 \mathrm{~b}$ exhibits new IR adsorption bands at 2181,1974 and $1140 \mathrm{~cm}^{-1}$, which could be related to stretching vibrations of $\mathrm{N}=\mathrm{C}=\mathrm{O}$ and $\mathrm{N}=\mathrm{O}$ groups, and to bending vibrations of $\mathrm{C}-\mathrm{N}$. These bands confirm the immobilization of $\mathrm{MB}$ on the biosorbent particles. 


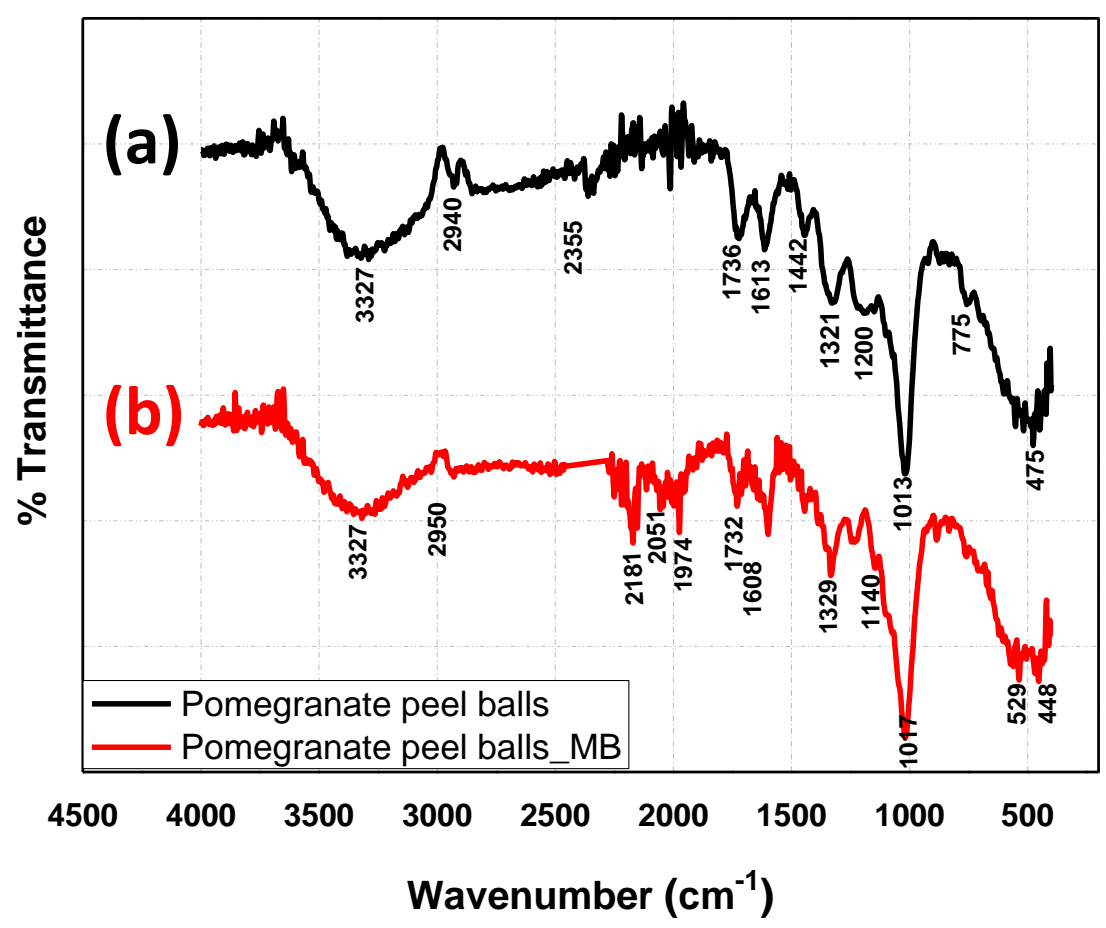

Figure 1. Infrared spectra of pomegranate peel balls before (a, black) and after (b, red) adsorption of Methylene Blue (MB).

\subsection{XPS analysis}

The XPS analysis of pomegranate peel is given in Figure 2. Figure 2a exhibits sharp C1s (285 $\mathrm{eV})$, and $\mathrm{O} 1 \mathrm{~s}(532 \mathrm{eV})$ peaks of pomegranate peel. After adsorption of the dye, noteworthy observations are the occurrence of the N1s peak $(400 \mathrm{eV})$ assigned to the dye, as well as S2p (Figure 2c) with two components at $164.4 \mathrm{eV}$ and $168.2 \mathrm{eV}$ (oxidized sulfur atoms). The XPS spectra of C1s shown in Figure 2b fitted with four components centered at $284.9 \mathrm{eV}, 286.6$ $\mathrm{eV}, 288.2 \mathrm{eV}$ and $289.1 \mathrm{eV}$, representing differences in chemical environment around carbon atoms. The peak at $284.9 \mathrm{eV}$ is typical of the $\mathrm{C}-\mathrm{C} / \mathrm{C}-\mathrm{H}$ bond; the component at $286.6 \mathrm{eV}$ is associated with $\mathrm{C}-\mathrm{O}$ bonding; the component at $288.2 \mathrm{eV}$ is most probably due to the semiacetal carbon atom in cellulosic materials, while a final minor component is located at 289.2 $\mathrm{eV}$ probably due to COOR types of carbon atoms. Survey spectra in Figures $2 \mathrm{~b}$ and $\mathrm{c}$ and compositions in Figure 2c indicate clear and significant changes experienced by pomegranate peel balls after the Methylene Blue adsorption process. 

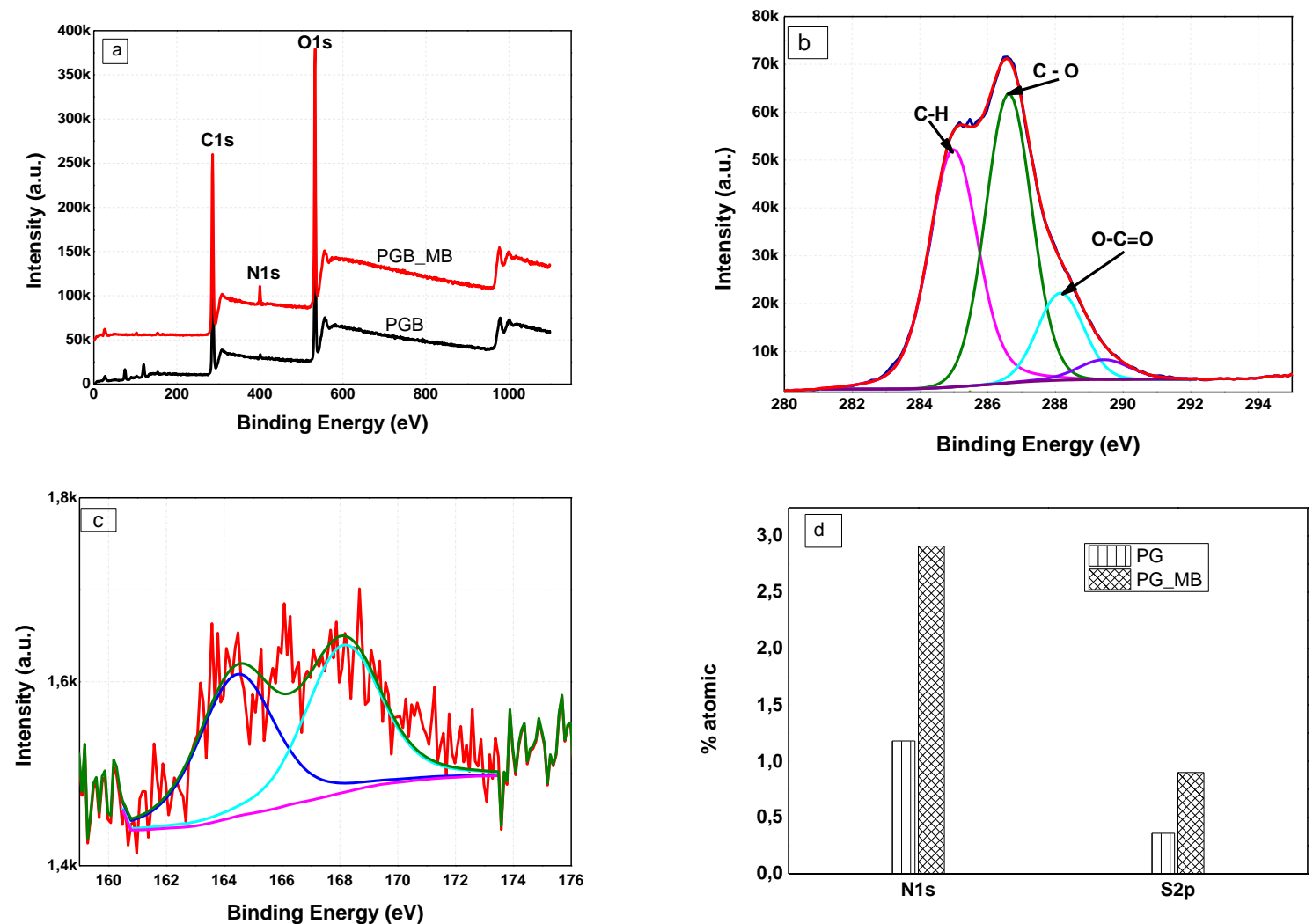

Figure 2. XPS survey spectra of pomegranate peel after and before adsorption of methylene bleu (a), C1s and S2p narrow regions for pomegranate peel balls after adsorption (b, c), and the atomic ratio of nitrogen and sulfur in PG peel balls (before and after adsorption of $\mathrm{MB}$ ) (d).

\subsection{Effect of $\mathrm{pH}$}

Elimination of Methylene Blue by the bio-balls is significantly affected by the solution $\mathrm{pH}$. Indeed, it acts both on the surface load of the material and on the distribution and speciation of cations [41,42]. The effect of $\mathrm{pH}$ on the adsorption rate of $\mathrm{MB}$ has been studied over a wide range of $\mathrm{pH}=1-10$. The effect of $\mathrm{pH}$ on the removal of $\mathrm{MB}$ is shown in Figure.3. It was observed that a gradual increase in the amount of MB adsorbed from $3.6 \mathrm{mg} / \mathrm{g}$ to $16.0 \mathrm{mg} / \mathrm{g}$ occurred when the $\mathrm{pH}$ values increased from 1 to 7 . As the $\mathrm{pH}$ increases, the double positively charged Methylene Blue (Scheme 1) becomes deprotonated but remains cationic in nature. IR results indicate the presence of carboxylates [39] that interact favorably with proton $\mathrm{H}^{+}$, thus hampering adsorption of the dye at low $\mathrm{pH}$. Elevating the $\mathrm{pH}$ reduces the concentration of $\mathrm{H}^{+}$, thus making it possible to accommodate more cationic MB dye at the surface via electrostatic 
interactions. In short, adsorption of $\mathrm{MB}$ is favored when the $\mathrm{pH}$ increases due to the drastic decrease in $\mathrm{H}^{+}$competing ions.

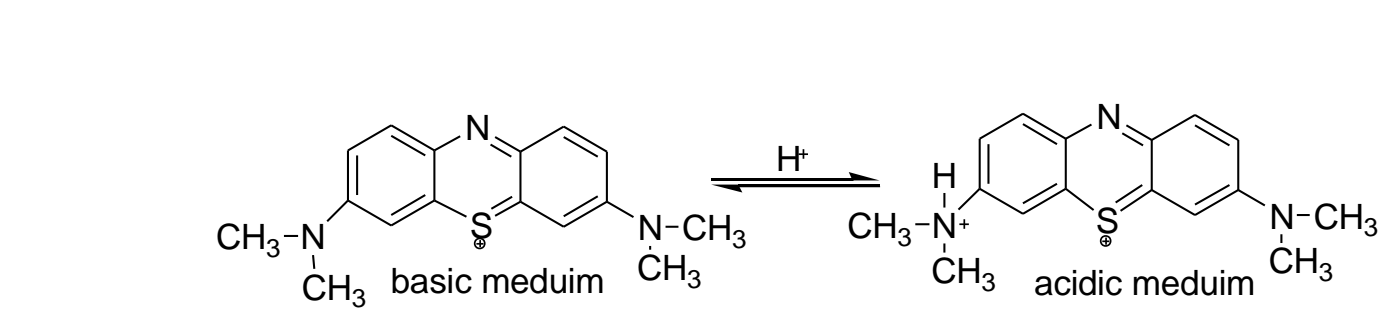

\section{Scheme1. Protonation of Methylene Blue in aqueous solution.}

This can be explained by the fact that at low $\mathrm{pH}$ values, the surface of the adsorbent would be surrounded by $\mathrm{H}^{+}$ions, which induces repulsion of the protonated form of Methylene Blue [43]. On the other hand, at high $\mathrm{pH}$, the concentration of $\mathrm{H}^{+}$decreases, which leads to a good interaction between the dye ions and the surface sites [44].

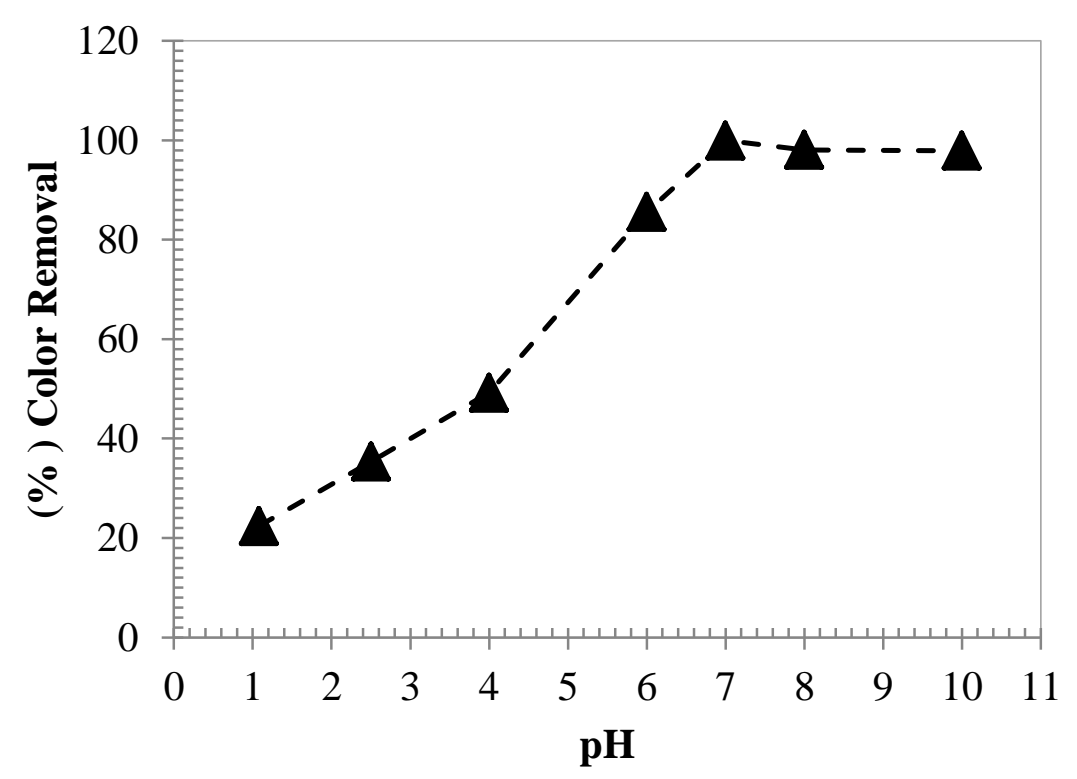

Figure 3. Effect of $\mathrm{pH}$ on $\mathrm{MB}$ removal by pomegranate peel balls (contact time $=2 \mathrm{~h}$, dose of pomegranate peel balls $=0.05$ g. $\mathrm{L}^{-1}$, MB concentration $=40 \mathrm{mg} \cdot \mathrm{L}^{-1}$, temperature $=28{ }^{\circ} \mathrm{C}$ ).

\subsection{Effect of temperature}

Temperature is an important factor that can affect the adsorption process. Adsorption of MB from an aqueous solution at different temperatures was studied in a range from 25 to $55^{\circ} \mathrm{C}$. 
Figure 4 illustrates the effect of temperature on adsorption for pomegranate peel balls. As can be clearly seen in Figure 4, adsorption capacity is increased to its maximum at $25{ }^{\circ} \mathrm{C}$. Above this temperature, it is observed that adsorption of the MB dye on pomegranate peel balls decreases as the temperature of the solution increases. Similar results have been obtained by various authors for adsorption of dyestuffs on various adsorbents $[45,46,47,48]$. This is due to the exothermic, spontaneous adsorption process and the weakening of the bonds between the dye molecules and the active sites of the adsorbents at high temperature. However, overheating adversely affects the adsorption process and can lead to an increase in desorption.

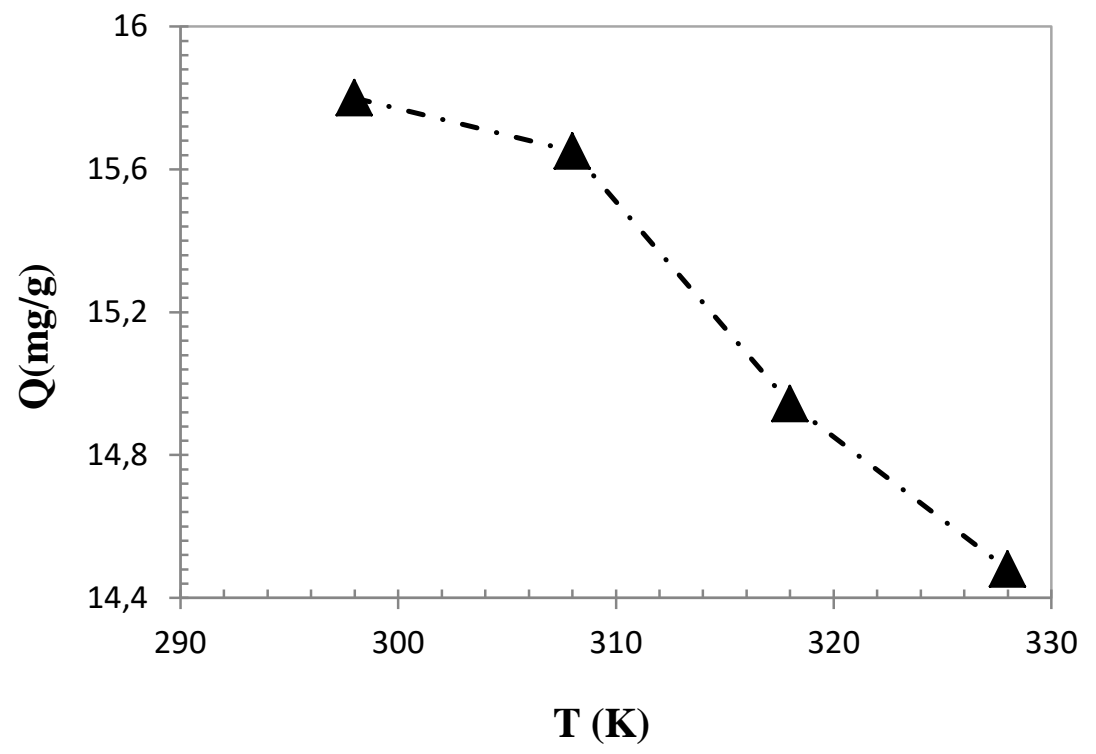

Figure 4. Effect of temperature on MB removal by pomegranate peel balls ( $\mathrm{pH} 7, \mathrm{BM}$ concentration $=40 \mathrm{mg} \mathrm{L}^{-1}$, contact time $=2 \mathrm{~h}$, dose of pomegranate peel balls $=0.05 \mathrm{~g} \mathrm{~L}^{-1}$ )

\subsection{Effect of contact time}

Adsorption of $\mathrm{MB}$ on the pomegranate peel balls in solution implies determination of contact time, which corresponds to a state of equilibrium of saturation of the support by the substrate. The results displayed in Figure 5 show that the adsorbed amount of MB increases rapidly in the first 60 minutes to reach an optimum of $98.2 \%$, and remain approximately constant after 120 minutes, indicating a steady state. This shows that the adsorption balance of the dye by the adsorbent used is very fast. Adsorption then slows down gradually. This is due to the availability of the large number of vacant adsorption sites on the surface of balls at the initial stage of adsorption. These lead to a decrease in adsorption rate, while a plateau corresponding to the steady state after 60 minutes is observed. 


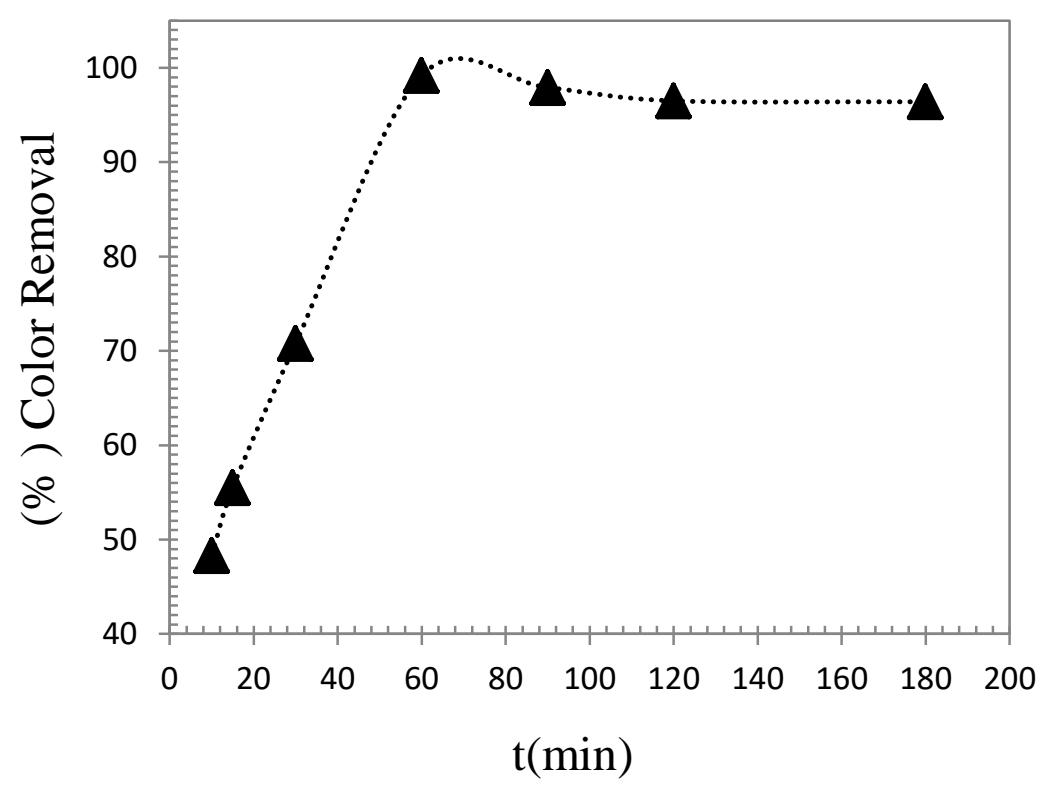

Figure 5. Effect of contact time on direct blue dye removal by pomegranate peel balls ( $\mathrm{pH} 7$, temperature $=28{ }^{\circ} \mathrm{C}, \mathrm{MB}$ concentration $=40 \mathrm{mg} \mathrm{L}^{-1}$, weight of pomegranate peel balls $=0.05$ $\left.\mathrm{g} \mathrm{L}^{-1}\right)$.

\subsection{Adsorption kinetics}

Adsorption of organic molecules by a solid in aqueous solution is a phenomenon with complex kinetics. In order to study MB adsorption processes on pomegranate peel balls, we used the pseudo-first order and pseudo-second order kinetic model. The pseudo-first order was expressed by the Lagergren equation (3) [27], while the pseudo-second order was expressed by equation (4) [49]:

$$
\log \left(q_{e}-q_{t}\right)=\log q_{e}-\frac{k_{1}}{2.303} t
$$

$$
\frac{t}{q}=\frac{1}{k_{2} q_{e}^{2}}+\frac{t}{q_{e}}
$$

Where $\mathrm{q}_{\mathrm{t}}$ and qe are the quantities adsorbed at times $\mathrm{t}$ and at equilibrium, and $\mathrm{K}_{1}, \mathrm{k}_{2}$ are the rate constants of the adsorption process of the pseudo-first order and pseudo-second order.

245 Figure 6 illustrates the results of the application to pseudo-first order and pseudo-second order kinetic models of Methylene Blue adsorption on pomegranate peel balls. The pseudo firstand pseudo-second order constants were determined by extrapolation of the log plot (Qe-Qt) versus time (t) (Figure 6(a)). The t/qt plot versus time (t), the pseudo first- and pseudo-second 
order constants $\mathrm{K}_{1}$ and $\mathrm{K}_{2}$, respectively, the regression coefficients $\mathrm{R}^{2}$, and the calculated values of the adsorbed quantities Qe are summarized in Table 1. These observations suggest that, for the first-order kinetic model, the correlation coefficient $\mathrm{R}^{2}$ is of the order of 0.495 , and the adsorption capacity is much lower than that obtained experimentally. On the other hand, the correlation coefficient for the pseudo-second kinetic model is of the order of 0.995 and is very close to unity. Equilibrium Qe adsorption amounts for the pseudo-first order and pseudo-second order kinetic models are $5.432 \mathrm{mg} / \mathrm{g}$ and $16.660 \mathrm{mg} / \mathrm{g}$, respectively. These results suggest that the adsorption process fits in well with the pseudo-second order model.
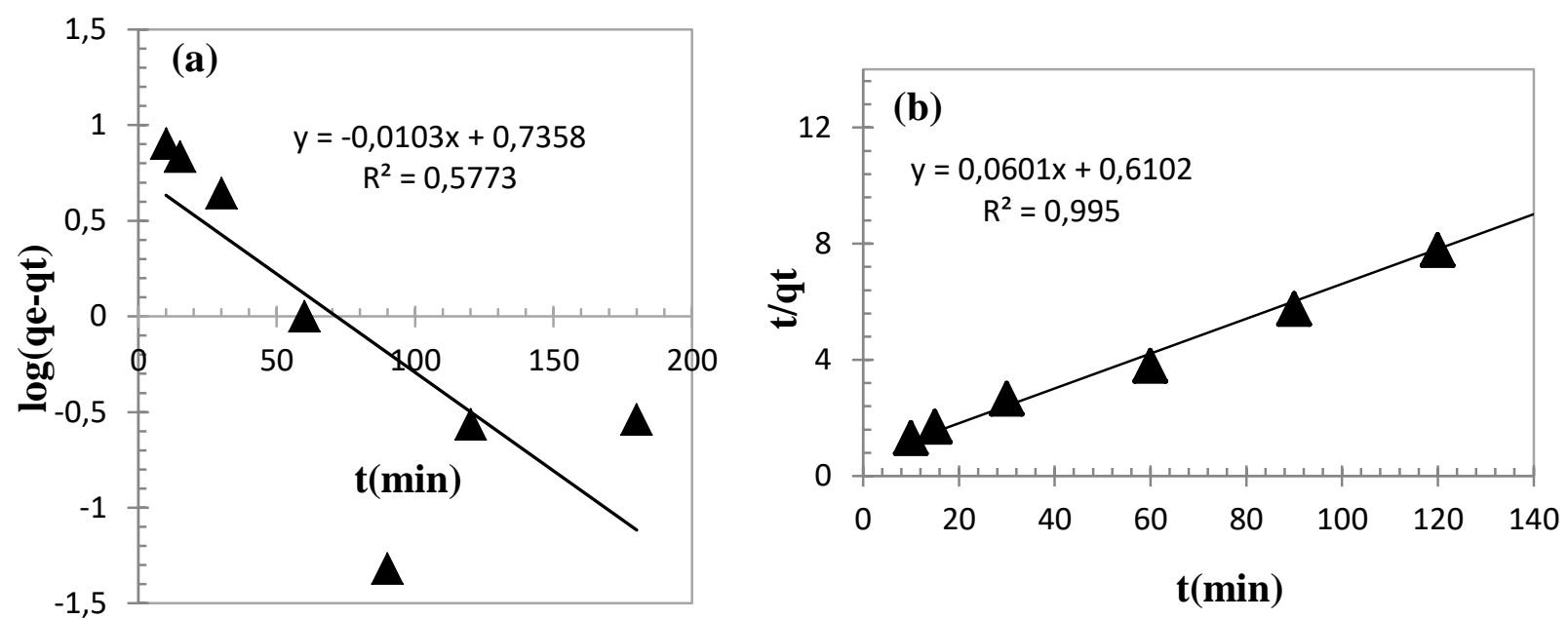

Figure 6. kinetics (a), pseudo-second order (b) kinetics for Methylene Blue adsorption onto pomegranate peel balls $\left(\mathrm{pH} 7\right.$, temperature $=25^{\circ} \mathrm{C}, \mathrm{MB}$ concentration $=40 \mathrm{mg} \mathrm{L}^{-1}$, weight of pomegranate peel balls $=50 \mathrm{mg}$ ).

Table 1. Adsorption kinetic parameters of MB, modeled by pseudo-first order and pseudosecond order models at different temperatures.

\begin{tabular}{|c|c|c|l|}
\hline Kinetic models & $\mathbf{Q}_{\mathrm{e}} \mathbf{c a l}(\mathbf{m g} / \mathbf{g})$ & $\mathbf{K}_{\mathbf{1}}\left(\mathbf{m i n}^{\mathbf{- 1}}\right)$ & $\mathbf{R}^{\mathbf{2}}$ \\
\hline Pseudo-first order & 5.432 & $2.310^{-2}$ & 0.495 \\
\hline Pseudo-second order & 16.660 & $0.3610^{-2}$ & 0.995 \\
\hline
\end{tabular}

Methylene Blue $\mathrm{C}_{0}=40 \mathrm{mg} / \mathrm{L}$ 


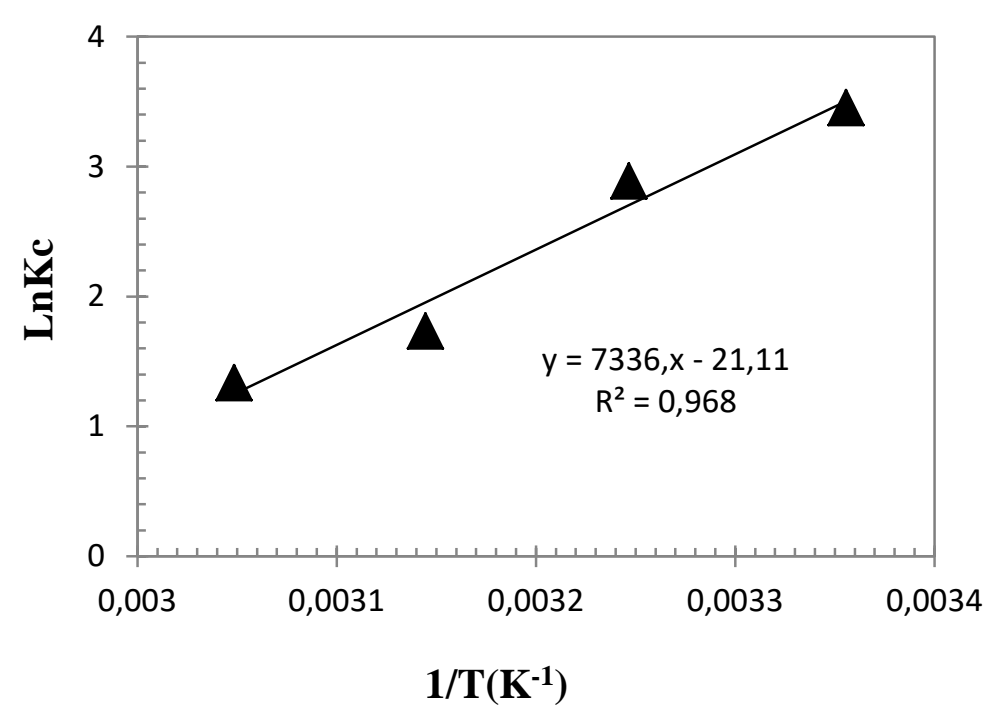

Figure 7. Plot of $\operatorname{Ln}\left(K_{c}\right) \vee \frac{1}{T}$ for removal of Methylene Blue by pomegranate peel balls.

Temperature is a very important parameter in the adsorption process in that it affects the interactions between the adsorbent adsorbate systems. The thermodynamic study reflects the feasibility and spontaneous nature of the adsorption process. Parameters such as free energy $\left(\Delta \mathrm{G}^{\circ}\right)$, enthalpy variation the values $\left(\Delta \mathrm{H}^{\circ}\right)$, and entropy variation $\left(\Delta \mathrm{S}^{\circ}\right)$ can be estimated from equilibrium constants at different temperatures. The $\Delta \mathrm{G}(\mathrm{kJ} / \mathrm{mol})$ of adsorption reaction is given by:

$$
\Delta \mathrm{G}^{\circ}=\mathrm{RTLnK}_{\mathrm{c}}
$$

$$
\mathrm{K}_{\mathrm{c}}=\frac{Q e}{C e}
$$

where $Q e$ and $C e$ are the adsorption capacity and the equilibrium concentration in the solution at adsorption equilibrium, respectively; $R$ is the universal gas constant $\left(8.314 \mathrm{~J} \mathrm{~mol}^{-1} \mathrm{~K}^{-1}\right)$, and $T$ stands for the absolute temperature (K). The values of $\Delta \mathrm{H}$ and $\Delta \mathrm{S}$ can be calculated from the Van't Hoff equation:

$$
\Delta \mathrm{G}=\Delta \mathrm{H}-\mathrm{T} \Delta \mathrm{S}
$$

Equation 6 was used to deduce $\Delta \mathrm{H}$ and $\Delta \mathrm{S}$ from the slope and the intercept of the of $\ln \mathrm{K}_{\mathrm{c}}-v s-1 / \mathrm{T}$ linear plot (Figure 7), respectively. 
The values of the thermodynamic parameters are given in Table 2 . The negative $\Delta \mathrm{G}$ values indicate spontaneous adsorption of MB on pomegranate peel balls. However, the higher was the reaction temperature the smaller the $\Delta \mathrm{G}$ value. Generally, a $-\Delta \mathrm{G}$ value between 0 and 20 $\mathrm{KJ} / \mathrm{mol}$ is consistent with the electrostatic interaction between the adsorption sites and the adsorbing molecules, meaning that the type of adsorption is physical adsorption [50]. The values of enthalpy $\left(\Delta \mathrm{H}^{\circ}\right)$ and entropy $\left(\Delta \mathrm{S}^{\circ}\right)$ were calculated to be $-61.0 \mathrm{~kJ} / \mathrm{mol} . \mathrm{K}$ and -175.5 $\mathrm{kJ} / \mathrm{mol} . \mathrm{K}$, respectively. The negative sign of $\Delta \mathrm{H}^{\circ}$ shows that the sorption of $\mathrm{MB}$ by pomegranate peel balls is exothermic.

Table 2. Thermodynamic parameters for adsorption of MB onto pomegranate peel balls.

\begin{tabular}{|c|c|c|c|c|}
\hline $\mathbf{T}(\mathbf{K})$ & $\boldsymbol{\Delta} \mathbf{G}(\mathbf{k J} / \mathbf{m o l})$ & $\mathbf{\Delta H}(\mathbf{k J} / \mathbf{m o l} . \mathbf{K})$ & $\Delta \mathbf{S}(\mathbf{J} / \mathbf{m o l} . \mathbf{K})$ & $\mathbf{R}^{\mathbf{2}}$ \\
\cline { 1 - 2 } $\mathbf{2 9 8}$ & -8.54 & & & \\
\cline { 1 - 2 } $\mathbf{3 0 8}$ & -7.37 & -70.00 & -175.5 & \multirow{2}{*}{0.968} \\
\cline { 1 - 2 } $\mathbf{3 1 8}$ & -4.57 & & & \\
\cline { 1 - 2 } $\mathbf{3 2 8}$ & -3.62 & & & \\
\hline
\end{tabular}

\subsection{Regeneration of bio-adsorbent}

Four consecutive adsorption-desorption cycles were carried out on the same adsorbent to study the regeneration capacity of the balls. Figure 8 shows the reusability performance of the beads: after the second adsorption-desorption cycle we notice a progressive decrease in the adsorbing power of our beads, which can be explained by the incomplete recovery of the active sites after regeneration. [51,52]. The adsorption performance of the beads was maintained after the second cycle, while the third and fourth cycles induced a slight decrease in the adsorbed amount of Methylene Blue. These results are indicative of balls re-adsorption performance, which ensures long-term use in wastewater treatment with dyes [51]. 


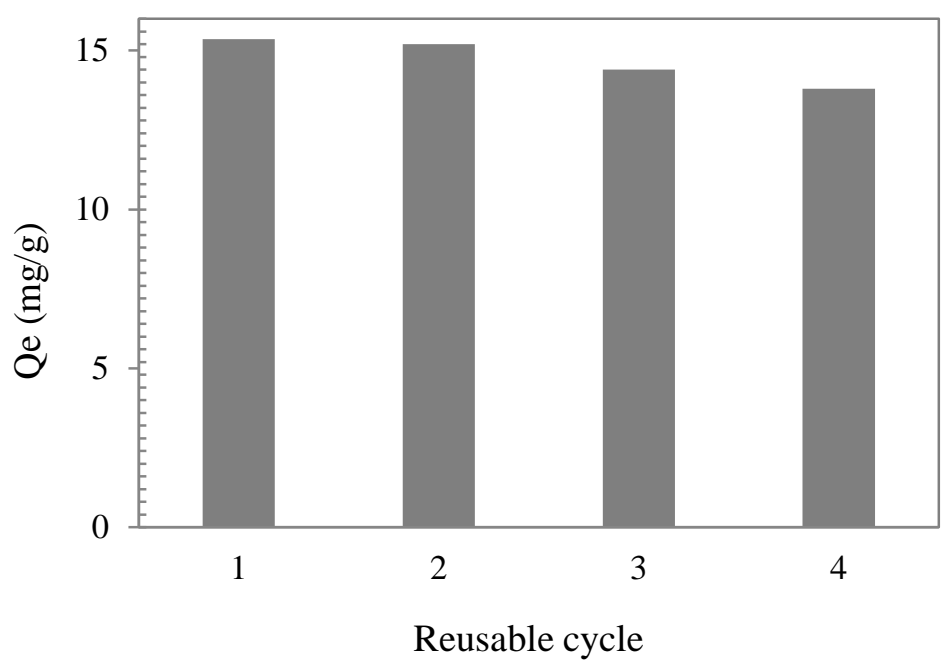

Figure 8. Recycling of pomegranate peel based bio-balls in the removal of Methylene Blue from aqueous solution $\left(\mathrm{C}_{0}=40 \mathrm{mg} / \mathrm{L}, \mathrm{pH}=7, \mathrm{~V}=20 \mathrm{~mL}\right)$.

3.9. Comparison of pomegranate peel ball adsorption properties with other adsorbents.

Table 3. Comparison of the maximum adsorption capacity of Methylene Blue on various adsorbents

\begin{tabular}{|c|c|c|c|c|c|c|}
\hline Adsorbent & $\begin{array}{c}\text { Qmax } \\
(\mathbf{m g} / \mathbf{g})\end{array}$ & $\begin{array}{c}\text { MB } \\
\text { removal } \\
(\mathbf{\%})\end{array}$ & $\mathbf{p H}$ & $\begin{array}{c}\text { Initial MB } \\
\text { concentration } \\
(\mathbf{m g} / \mathbf{L})\end{array}$ & $\begin{array}{c}\text { Adsorbent } \\
\text { dosage (g) }\end{array}$ & Ref. \\
\hline Coir pith & 5.87 & 97 & 6.9 & $10-40$ & $100 \mathrm{mg} / 50 \mathrm{~mL}$ & [53] \\
\hline Rice husk & 9.83 & 93.2 & 7 & 60 & 1100 & {$[54]$} \\
\hline $\begin{array}{c}\text { Raw Brazil nut } \\
\text { shells }\end{array}$ & 7.81 & - & 6.5 & 25 & $0.05 \mathrm{~g} / 25 \mathrm{~mL}$ & {$[55]$} \\
\hline $\begin{array}{c}\text { Orange peel } \\
\text { Pomegranate } \\
\text { peel powder } \\
\text { particles }\end{array}$ & 14.2 & - & 4 & 50 & $0.08 \mathrm{~g} / 100 \mathrm{~mL}$ & {$[39]$} \\
\hline $\begin{array}{c}\text { Pomegranate } \\
\text { peel powder } \\
\text { particles }\end{array}$ & 184.9 & $49.3^{\mathrm{a}}$ & 5.6 & 300 & $0.08 \mathrm{~g} / 100 \mathrm{~mL}$ & {$[39]$} \\
\hline $\begin{array}{c}\text { Pomegranate } \\
\text { peel balls }\end{array}$ & 15.7 & 99.20 & & 40 & $0.05 \mathrm{~g} / 20 \mathrm{~mL}$ & This work \\
\hline
\end{tabular}

acalculated from the published data in [39].

315 Table 3 compares the maximum adsorption capacity of the actual pomegranate peel balls with those of other bio-based agrowastes. Although within the same order of magnitude, the actual 
designed peel balls behave remarkably well compared with other agrowastes and adsorb the quasi total amount of dye dissolved in the aqueous solution. They thus appear promising for future developments. The lyophilization approach, which follows the peel ball freezing step, certainly merits further investigation in view of harnessing adsorption capacity.

\section{Conclusion}

In this work, a low-cost pomegranate peel bio-ball demonstrated the ability to adsorb Methylene Blue from aqueous solutions. The removal of this cationic dye is maximal at $\mathrm{pH} 7$. The results of removing this cationic dye from aqueous solutions by pomegranate peel bioballs correlated with the pseudo-second order kinetic model. Adsorption equilibrium is reached within $60 \mathrm{~min}$. The thermodynamic study indicates the exothermic and spontaneous nature of the adsorption process. The agrowaste-derived balls have excellent adsorption and regeneration properties. Reuse of balls not only reduces production cost but also reduces secondary pollution. This study concludes that pomegranate peel can be used to prepare lowcost adsorbents of dyes (herein Methylene Blue), thereby addressing the United Nations Sustainable Development Goal 6 (SDG 6), which concerns "clean water and sanitation for all".

Declaration of interest: the authors declare no conflict of interest.

\section{References}

[1]. N. Sivri, İ. Toroz, Pollutants of textile industry wastewater and assessment of its discharge limits by water quality standards. Turk. J. Fish Aquat. Sci.103, 97-103 (2007)

[2] A.M. Duda, Addressing nonpoint sources of water pollution must become an international priority. Waf. Sci. Tech. 28, 1-11 (2018).

[3] T.Ã. Rajaram, A. Das, Water pollution by industrial effluents in India : Discharge scenarios and case for participatory ecosystem specific local regulation. Futures. 40, 56-69 (2008).

[4] B. Kasprzyk-Hordern, R.M. Dinsdale, A.J. Guwy, The removal of pharmaceuticals, personal care products, endocrine disruptors and illicit drugs during wastewater treatment and its impact on the quality of receiving waters. Water Res. 43, 363-380 (2009).

[5] M. Petrović, S. Gonzalez, D. Barceló. Analysis and removal of emerging contaminants in wastewater and drinking water, TrAC - Trends Anal. Chem. 22, 685-696 (2003). 
[6] G. Lettinga, A. F. M. van Velsen, S. W. Hobma, W. de Zeeuw, A. Klapwijk. Use of the upflow sludge blanket (USB) reactor concept for biological wastewater treatment, Biotechnol. Bioeng. 22, 699-734(1980).

[7] K. Kadirvelu, M. Palanival, R. Kalpana, S. Rajeswari, Activated carbon from an agricultural by-product, for the treatment of dyeing industry wastewater, Bioresour. Technol. 74, 263-265 (2000).

[8] A. Khaled, A. El Nemr, A. El-Sikaily, O. Abdelwahab, Removal of Direct N Blue-106 from artificial textile dye effluent using activated carbon from orange peel: Adsorption isotherm and kinetic studies. J. Hazard. Mater. 165 , 100-110 (2009).

[9] M.C. Ribas, M.A. Adebayo, L.D.T. Prola, E.C. Lima, R. Cataluña, L.A. Feris, M.J. Puchana-rosero, F.M. Machado, F.A. Pavan, T, CalveteComparison of a homemade cocoa shell activated carbon with commercial activated carbon for the removal of reactive violet 5 dye from aqueous solutions, Chem. Eng. J. 248, 315-326 (2014).

[10] M. Daoud, O. Benturki, Z. Kecira, P. Girods, A. Donnot, Removal of reactive dye (BEZAKTIV Red S-MAX) from aqueous solution by adsorption onto activated carbons prepared from date palm rachis and jujube stones, J. Mol. Liq. 243, 799-809 (2017).

[11] H. Shokry, M. Elkady, H. Hamad, Nano activated carbon from industrial mine coal as adsorbents for removal of dye from simulated textile wastewater: Operational parameters and mechanism study, J. Mater. Res. Technol. 8 , 4477-4488 (2019).

[12 ] M. Wang, G. Li, L. Huang, J. Xue, Q. Liu, N. Bao, J. Huang, Study of ciprofloxacin adsorption and regeneration of activated carbon prepared from Enteromorpha prolifera impregnated with $\mathrm{H}_{3} \mathrm{PO}_{4}$ and sodium benzenesulfonate, Ecotoxicol. Environ. Safe. 139, 3642 (2017).

[13]Y. Zhou, J. Lu, Y. Zhou,Y. Liu, Recent advances for dyes removal using novel adsorbents: A review. Environ. Pollut. A. 252, 352-365 (2019)

[14] S. El-Nahas, H.M. Salman, W.A. Seleeme, Aluminum building scrap wire, take-out food container, potato peels and bagasse as valueless waste materials for nitrate removal from water supplies. Chem. Afr., 2, 143-162 (2019).

[15] S. Zafar, M.I. Khan, M.H. Lashari, M. Khraisheh, F. Almomani, M. L. Mirza, N. Khalid Removal of copper ions from aqueous solution using $\mathrm{NaOH}$-treated rice husk. Emergent Mater. (2020). https://doi.org/10.1007/s42247-020-00126-w

[16] R. Paradelo, X. Vecino, A. Belén Moldes, M. T. Barral. Potential use of composts and vermicomposts as low-cost adsorbents for dye removal: an overlooked application. Environ.

Sci. Pollut. Res. 26, 21085-21097 (2019).

[17] Z. N. Garba, I. Lawan, W. Zhou, M. Zhang, L. Wang, Z. Yuan. Microcrystalline cellulose (MCC) based materials as emerging adsorbents for the removal of dyes and heavy metals - A review. Sci. Total Environ. 717, 135070 (2020).

[18] N. Nasuha, B.H. Hameed, A.T.M. Din, Rejected tea as a potential low-cost adsorbent for the removal of methylene blue. J. Hazard. Mater. 175, 126-132 (2010).

[19] B.H. Hameed, Spent tea leaves : A new non-conventional and low-cost adsorbent for removal of basic dye from aqueous solutions. J. Hazard. Mater. 161, 753-759 (2009).

[20] S. Wong, H.H. Tumari, N. Ngadi, N.B. Mohamed, O. Hassan, R. Mat, N.A. Saidina Amin, Adsorption of anionic dyes on spent tea leaves modified with polyethyleneimine (PEISTL). J. Clean. Prod. 206, 394-406 (2019).

[21] M.A. Ahsan, M.T. Islam, C. Hernandez, H. Kim, Y. Lin, M.L. Curry, J. GardeaTorresdey, J.C. Noveron, Adsorptive removal of sulfamethoxazole and bisphenol A from 
contaminated water using functionalized carbonaceous material derived from tea leaves. $\mathrm{J}$. Environ. Chem. Eng. 6, 4215-4225 (2018).

[22] Y.C. Wong, M.S.R. Senan, N.A. Atiqah, Removal of Methylene Blue and Malachite Green dye using different form of coconut fibre as absorbent. J. Basic Appl. Sci. 9, 172-177 (2013).

[23] M. Baek, C.O. Ijagbemi, D. Kim, Removal of Malachite Green from aqueous solution using degreased coffee bean. J. Hazard. Mater.176, 820-828(2010).

[24] I. Anastopoulos, M. Karamesouti, A.C. Mitropoulos, G.Z. Kyzas, A review for coffee adsorbents. J. Mol. Liq. 229, 555-565(2017).

[25] Y. Miyah, A. Lahrichi, M. Idrissi, Removal of cationic dye -Methylene Blue- from aqueous solution by adsorption onto corn cob powder calcined. J. Mater. Environ. Sci. 7, 96104(2016).

[26] M.P. Elizalde-González, J. Mattusch, R. Wennrich, Chemically modified maize cobs waste with enhanced adsorption properties upon methyl orange and arsenic. Bioresour. Technol. 99, 5134-5139(2008).

[27] L. Sun, S. Wan, D. Yuan, Z. Yu, Adsorption of nitroimidazole antibiotics from aqueous solutions on self-shaping porous biomass carbon foam pellets derived from Vallisneria natans waste as a new adsorbent. Sci. Total Environ. 664, 24-36 (2019).

[28] X. Yong, S. Raza, J. Deng, Y. Wu, Biomass ferulic acid-derived hollow polymer particles as selective adsorbent for anionic dye. React. Funct. Polym. 132, 9-18 (2018).

[29] Ö. Gerçel, H.F. Gerçel, A.S. Koparal, Ü.B. Öğütveren, Removal of disperse dye from aqueous solution by novel adsorbent prepared from biomass plant material, J. Hazard. Mater. 160, 668-674 (2008).

[30] T. S. Chandra, S.N.Mudliar, S.Vidyashankar ,S.Mukherji, R.Sarada, K.Krishnamurthi, V.S.Chauhan, Defatted algal biomass as a non- conventional low- cost adsorbent: Surface characterization and Methylene Blue adsorption characteristics, Bioresour. Technol. 184, $395-$ 404 (2015)

[31] https://www.lesfruitsetlegumesfrais.com/fruits-legumes/fruits-exotiques-ettropicaux/grenade/comment-ca-pousse .Last accessed 24 September 2020.

[32]T. Roukas, P. Kotzekidou, Pomegranate peel waste: a new substrate for citric acid production by Aspergillus niger in solid-state fermentation under non-aseptic conditions, Environ. Sci. Pollut. Res. 27, 13105-13113(2020).

[33] E. H. Papaioannou, S.T. Mitrouli, S.I. Patsios, M. Kazakli, A. J. Karabelas, Valorization of pomegranate husk - Integration of extraction with nanofiltration for concentrated polyphenols recovery. J. Environ. Chem. Eng. 8, 103951 (2020).

[34] H. Saad, A. Pizzi, B. Charrier, N. Ayed, K. Rode, F. Charrier, Valorization of Tunisian pomegranate peel tannins in green adhesives formulation. J. Renew. Mater. 3, 34-43(2015).

[35] P. D. Pathak, S. A. Mandavgane, B. D. Kulkarni, Valorization of pomegranate peels: A biorefinery approach. Waste Biomass Valori. 8, 1127-1137 (2016). .

[36] M.E.M. Ali, H. Abdelsalam, N. S. Ammar, H.S. Ibrahim. Response surface methodology for optimization of the adsorption capability of ball-milled pomegranate peel for different pollutants, J. Mol. Liq. 250, 433-445 (2018).

[37] F. Gündüz, B. Bayrak.Biosorption of malachite green from an aqueous solution using pomegranate peel: Equilibrium modelling, kinetic and thermodynamic studies. J. Mol. Liq. 243, 790-798 (2017) 
[38] S. S.Nehaba.Synthetic textile red dye removal from aqueous

solution by adsorption onto pomegranate peel. J. Babylon Univ./Eng. Sci. 25, 1439-1447 (2017). https://www.iasj.net/iasj?func=article\&aId=126905 Last accessed 12 October 2020.

[39] A. H. Jawad, A. S.Waheeb, R.Abd Rashid, W. I.Nawawi,E.Yousif. Equilibrium isotherms, kinetics, and thermodynamics studies of methyleneblue adsorption on pomegranate (Punicagranatum) peels as a naturallow-cost biosorbent. Desalin. Water Treat. 105, 322-331 (2018).

[40] R. Msaadi, G. Yilmaz, A. Allushi, S. Hamadi, S. Ammar, M.M. Chehimi, Y. Yagci, Highly selective copper ion imprinted clay/polymer nanocomposites prepared by visible light initiated radical photopolymerization. Polymers 11, 286 (2019).

[41] X.P. Luo, S.Y. Fu, Y.M. Du, J.Z. Guo, B. Li, Adsorption of methylene blue and malachite green from aqueous solution by sulfonic acid group modified MIL-101, Micropor. Mesopor. Mater. 237, 268-274 (2017).

[42] J. Chang, J. Ma, Q. Ma, D. Zhang, N. Qiao, M. Hu, H. Ma, Adsorption of Methylene Blue onto $\mathrm{Fe}_{3} \mathrm{O}_{4} /$ activated montmorillonite nanocomposite. Appl. Clay Sci. 119,132-140 (2016).

[43] T.K. Sen, S. Afroze, H. M. Ang, Equilibrium, kinetics and mechanism of removal of Methylene Blue from aqueous solution by adsorption onto pine cone biomass of Pinus radiata. Water, Air Soil Pollut. 218, 499-515 (2010).

[44 ] M. Arami, N.Y. Limaee, N.M. Mahmoodi, N.S. Tabrizi, Equilibrium and kinetics studies for the adsorption of direct and acid dyes from aqueous solution by soy meal hull, $\mathrm{J}$. Hazard. Mater. 135, 171-179 (2006).

[45] O. Hamdaoui, Batch study of liquid-phase adsorption of methylene blue using cedar sawdust and crushed brick, J. Hazard. Mater. 135, 264-273 (2006).

[46] J.M. Chern, C.Y. Wu, Desorption of dye from activated carbon beds: Effects of temperature, $\mathrm{pH}$, and alcohol, Water Res. 35, 4159-4165 (2001).

[47] Y.S. Ho, G. McKay, Sorption of dye from aqueous solution by peat, Chem. Eng. J. 70 : 115-124 (1998).

[48] M.S. Chiou, H.Y. Li, Equilibrium and kinetic modeling of adsorption of reactive dye on cross-linked chitosan beads, J. Hazard. Mater. 93,233-248 (2002).

[49] S.H. Chien, W.R. Clayton, Application of Elovich Equation to the Kinetics of Phosphate Release and Sorption in Soils, Soil Sci. Soc. Am. J. 44,265-268 (1980).

[50] C.C. Liu, M. Kuang-Wang, Y.S. Li, Removal of nickel from aqueous solution using wine processing waste sludge, Ind. Eng. Chem. Res. 44,1438-1445 (2005).

[51] K.W. Jung, B.H. Choi, M.J. Hwang, T.U. Jeong, K.H. Ahn,Fabrication of granular activated carbons derived from spent coffee grounds by entrapment in calcium alginate beads for adsorption of acid orange 7 and Methylene Blue, Bioresour. Technol. 219, 185-195 (2016).

[52] T.T.C. Truong, N.T.T. Vo, K.D. Nguyen, H.M. Bui, Preparation of cellulose-based hydrogel derived from tea residue for the adsorption of methylene blue, Cellul. Chem. Technol. 53,573-582 (2019).

[53] D. Kavitha, C. Namasivayam, Experimental and kinetic studies on Methylene Blue adsorption by coir pith carbon. Bioresour. Technol. 98, 14-21 (2007). 
[54] Y. C. Sharma, Uma, Optimization of parameters for adsorption of Methylene Blue on a low-cost activated carbon. J. Chem. Eng. Data. 55, 435-439. (2010). .

[55] S. M. De Oliveira Brito, H. M. C. Andrade, L. F. Soares, R. P. de Azevedo, Brazil nut shells as a new biosorbent to remove Methylene Blue and Indigo Carmine from aqueous solutions. J. Hazard. Mater. 174, 84-92 (2010). .

[56] T. A. Salman, M. I. Ali, Potential application of natural and modified orange peel as an eco-friendly adsorbent for Methylene Blue dye. Iraqi. J. Sci. 57, 1-13 (2016). 